\section{Novel evidence for a greater burden of ambient air pollution on cardiovascular disease}

\author{
Pier Mannuccio Mannucci, ${ }^{1}$ Sergio Harari $^{2}$ and Massimo Franchini ${ }^{3}$ \\ ${ }^{1}$ Scientific Direction, IRCCS Ca' Granda Maggiore Policlinico Hospital Foundation, Milan; \\ ${ }^{2}$ Department of Pneumology and Semi-Intensive Care Unit, Department of Respiratory \\ Physiopathology and Pulmonary Hemodynamics, Ospedale San Giuseppe MultiMedica, \\ Milan and ${ }^{3}$ Department of Haematology and Transfusion Medicine, "Carlo Poma" Hospital, \\ Mantua, Italy
}

\section{ABSTRACT}

A mbient and household air pollution is a major health problem worldwide, contributing annually to approximately seven million of allcause avoidable deaths, shorter life expectancy, and significant direct and indirect costs for the community. Air pollution is a complex mixture of gaseous and particulate materials that vary depending on their source and physicochemical features. Each material has detrimental effects on human health, but a number of experimental and clinical studies have shown a strong impact for fine particulate matter $\left(\mathrm{PM}_{2.5}\right)$. In particular, there is more and more evidence that $\mathrm{PM}_{2.5}$ exerts adverse effects particularly on the cardiovascular system, contributing substantially (mainly through mechanisms of atherosclerosis, thrombosis and inflammation) to coronary artery and cerebrovascular disease, but also to heart failure, hypertension, diabetes and cardiac arrhythmias. In this review, we summarize knowledge on the mechanisms and magnitude of the cardiovascular adverse effects of shortand long-term exposure to ambient air pollution, particularly for the $\mathrm{PM}_{2.5}$ size fraction. We also emphasize that very recent data indicate that the global mortality and morbidity burden of cardiovascular disease associated with this air pollutant is dramatically greater than what has been thought up to now.

\section{Introduction}

Pollution of the ambient (outdoor) and household (indoor) air is recognized as one of the main risk factors for premature death, morbidity and disability-adjusted life-years, leading to significant direct and indirect costs for the community. ${ }^{1.3}$ The World Health Organization (WHO) warns us that globally ambient and household air is dangerously polluted for nine out of ten people, leading every year to at least seven million avoidable deaths, ${ }^{3,4}$ mainly from such atherothrombotic cardiovascular diseases (CVD) as coronary artery and cerebrovascular disease, but also to other non-communicable diseases such as cancer and chronic obstructive pulmonary disease. ${ }^{5,6}$ Diseases associated with air pollution are responsible for three times more premature deaths than AIDS, tuberculosis and malaria combined, and 15 times more than all wars and other violent causes.

The air pollutome is a complex mixture of gases (nitrogen oxides, ozone, sulfur dioxide, ammonia and carbon monoxide), volatile droplets (quinones and polycyclic aromatic hydrocarbons), and primary and secondary particulate matter (PM). Secondary PM forms in the air from primary precursors such as nitrogen dioxide, sulphur dioxide, ammonia, and volatile organic components. The physicochemical composition of air pollution varies, depending on environmental factors such as geographical and meteorological conditions and the prevailing sources, i.e. industrial activity, agriculture, and road, sea and air traffic.' Fossil fuel combustion is a major source of ambient air pollution, whereas burning of biomass used for cooking and heating is the most important source of household air pollution, particularly in low- and middle-income countries. There is robust epidemiological evi-
Ferrata Storti Foundation
Haematologica 2019
Volume 104(12):2349-2357

\section{Correspondence:}

PIER MANNUCCIO MANNUCCI

piermannuccio.mannucci@policlinico.mi.it

Received: April 18, 2019.

Accepted: June 19, 2019.

Pre-published: October 31, 2019.

doi:10.3324/haematol.2019.225086

Check the online version for the most updated information on this article, online supplements, and information on authorship \& disclosures: www.haematologica.org/content/104/12/2349

(C)2019 Ferrata Storti Foundation

Material published in Haematologica is covered by copyright. All rights are reserved to the Ferrata Storti Foundation. Use of published material is allowed under the following terms and conditions:

https://creativecommons.org/licenses/by-nc/4.0/legalcode. Copies of published material are allowed for personal or internal use. Sharing published material for non-commercial purposes is subject to the following conditions: https://creativecommons.org/licenses/by-nc/4.0/legalcode, sect. 3. Reproducing and sharing published material for commercial purposes is not allowed without permission in writing from the publisher. 
dence that PM is an extremely dangerous component for human health so that it may be considered a reliable proxy of the burden of ambient air pollution on morbidity and mortality. PM is a complex and heterogeneous mixture commonly classified on the basis of size as coarse (aerodynamic diameter $<10 \mu \mathrm{m} ; \mathrm{PM}_{10}$ ), fine (diameter $<2.5$ $\left.\mu \mathrm{m} ; \mathrm{PM}_{2.5}\right)$, or ultrafine $\left(<0.1 \mu \mathrm{m} ; \mathrm{PM}_{0.1}\right)$ fractions. ${ }^{8}$

Even though there is much evidence on the deleterious impact of air pollution on multiple body organs and systems ${ }^{6}$ a recent joint statement from the European Respiratory Society (ERS) and the American Thoracic Society (ATS) identified the cardiovascular system as the main target of air pollution, due, in particular, to $\mathrm{PM}_{2.5}{ }^{9,10}$ $\mathrm{PM}_{2.5}$ penetrates deep into the lower respiratory tract, escapes host defense and alveolar clearing mechanisms, and may reach the blood stream and organs (including the placenta and the brain) through translocation across biological membranes. Moreover, the large surface of $\mathrm{PM}_{2.5}$ facilitates the adsorption of organic material, heavy metals and other toxic substances, and offers room for oxygen radical generation in the lungs and blood.

The joint ERS/ATS statement is supported by a number of studies that in the last 20-30 years have unequivocally linked air pollution to CVD as the leading cause of global mortality, morbidity and disability. ${ }^{11,12}$ The most recent report by the Global Burden of Disease (GBD), which provides a source of annually updated, age- and sex-specific global data on all-cause mortality and related risk factors, indicates that at least 19 of the 56 million annual deaths worldwide are attributed to CVD; this is many more than to cancer (9.5 millions) and chronic obstructive pulmonary disease (3.9 millions). ${ }^{1}$ The same report also estimated that ambient air pollution ranks eighth in a list of 79 mortality risk factors. ${ }^{12}$ The magnitude of this risk is explained by the pervasive, persistent and unavoidable exposure to air pollution, resulting in a high population-attributable risk fraction.

With this background, we aim to update knowledge on the effects on the cardiovascular system of acute (shortterm) and chronic (long-term) exposure to ambient air pollution. We also draw attention to new data indicating that the global burden of $\mathrm{PM}_{2.5}$ pollution on mortality and morbidity from CVD and other non-communicable diseases is much greater than that previously established by the two major sources of information, i.e. the $\mathrm{WHO}$ and the GBD.

\section{Biomechanisms of atherothrombosis associated with air pollution}

The biological mechanisms through which air pollution, and particularly the $\mathrm{PM}_{2.5}$ size fraction, influence the occurrence of cardiovascular events are complex, multiple, and interdependent. ${ }^{13,14}$ Following inhalation, $\mathrm{PM}_{2.5}$ leads to the production of pro-oxidative (i.e. reactive oxygen species) and pro-inflammatory biological mediators (i.e. such cytokines as interleukin- 6 and tumor necrosis factor), acute-phase reactants such as C-reactive protein, and vasoactive hormones such as the endothelins. These are produced in the lungs and released into the blood stream and onto the vessel wall. ${ }^{15-17}$ The secretion of adhesion molecules by the inflamed pulmonary endothelial cells results in binding and activation of leukocytes and platelets, with the generation of tissue factor-bearing microparticles that are hemostatically active and that lead to systemic activation of blood coagulation. ${ }^{18-20}$ Accordingly, high $\mathrm{PM}_{2.5}$ concentrations are accompanied by such hypercoagulability biomarkers as high plasma levels of fibrinogen and D-dimer and enhanced thrombin formation. ${ }^{21}$ Besides the thromboinflammatory activities of $\mathrm{PM}_{2.5}$, another biomechanism of the CVD elicited by $\mathrm{PM}$ is the stimulation of the airway sensory nerves, resulting in the imbalance of the autonomic control of the heart and reduced heart rate variability, a risk factor for sudden death and severe arrythmias. ${ }^{22,23}$ Experimental data are paralleled by studies in humans that have shown an inverse relationship between PM exposure and heart rate variability. ${ }^{2426}$ A similar underlying mechanism (i.e. autonomic imbalance affecting vascular tone and reactivity) has been advocated to explain the association between exposure to air pollutants and increased blood pressure. ${ }^{27,28} \mathrm{PM}$ inhibits the production of the endogenous vasodilator nitric oxide, whose reduced bioavailability may contribute to increased blood pressure. ${ }^{29,30}$ Furthermore, experimental studies have shown that chronic PM exposure leads to the progression of atherosclerotic vascular lesions through pro-inflammatory mechanisms. ${ }^{31}$ For instance, the intratracheal acute administration to hyperlipidemic rabbits of ambient $\mathrm{PM}_{10}{ }^{31}$ and the long-term exposure to $\mathrm{PM}_{2.5}$ of genetically susceptible, apolipoprotein E-deficient mice enhance the growth of atherosclerotic plaques. ${ }^{32}$ The clinical relevance of the atherogenic effects of air pollution was confirmed by studies in humans, showing a positive correlation between the exposure to higher PM levels in the air and the degree of carotid intima-medial thickness and coronary artery calcification. ${ }^{33,34}$ Figure 1 summarizes the main mechanisms of PM-induced cardiovascular effects that act synergistically in the frame of a multifactorial impact on cardiovascular events. Additional mechanisms have been advocated although with less robust evidence, such as PM-induced activation of the hypothalamic pituitary adrenal axis, epigenomic dysregulation, and perturbation of the gut microbiome..$^{35}$

\section{Air pollution and cardiovascular diseases}

In the last few years, the assessment of exposure to ambient air pollution has become more and more accurate through the acquisition of satellite data and their integration with ground station measurements. With this background, Rajagopalan et al. ${ }^{11}$ summarized the degree of evidence linking air pollution to different CVD. Most of the well-established evidence concerns all-cause and cardiovascular mortality, followed by emerging evidence (although this still awaits confirmation) for hypertension, diabetes, non-fatal myocardial infarction, unstable angina, non-fatal stroke, and heart failure, whereas there is still insufficient evidence for venous thromboembolism and atrial fibrillation. Short-term effects of air pollution related to daily or multi-day exposure were methodologically evaluated by means of time-series or case-crossover studies. Evaluation of long-term effects was based upon cohort and crossover studies that captured the population impact of exposure over several years. ${ }^{36}$ Mechanistically, while short-term exposure mainly causes endothelium-mediated processes (such as impaired vasodilation and coronary vasoconstriction), oxidative stress and thromboinflammation are likely to be the predominant mechanisms for the long-term effects. ${ }^{14,36,37}$

\section{Short-term effects}

The association between the daily and multi-day variability of air pollution and adverse health outcomes was 
established in the first half of the last century. The smog accidents in the Meuse Valley (Belgium, 1930), Donora (Pennsylvania, 1948), and London (UK, 1952) caused peaks of increased hospitalization and deaths and it was these that first established a link between acute exposure to air pollution and adverse cardiopulmonary events. ${ }^{38,39}$ Since then, a large number of additional studies have evaluated the effects of PM on daily and multi-day changes in cardiovascular morbidity and mortality.

Data from 50 million people living in the 20 largest urban areas of the USA (the National Morbidity, Mortality and Air Pollution Study; NMMAPS) showed that, for each $10 \mu \mathrm{g} / \mathrm{m}^{3}$ rise in $\mathrm{PM}_{10}$ recorded on the day before death, there was a $0.68 \%$ increase in cardiopulmonary mortality. ${ }^{40}$ In Europe, the Air Pollution and Health European Approach (APHEA-2) study of 43 million people living in 29 large cities estimated a $0.76 \%$ increase in cardiovascular deaths for each $10 \mu \mathrm{g} / \mathrm{m}^{3}$ rise in $\mathrm{PM}_{10}{ }^{41}$ These data are consistent with those of the Meta-analysis of Italian Studies on the Short-term Effects of Air Pollution (MISA). ${ }^{42}$ In addition, the multi-city Air Pollution and Health European and North American Approach (APHENA) showed that a $10 \mu \mathrm{g} / \mathrm{m}^{3}$ acute rise in $\mathrm{PM}_{10}$ was associated with $0.2-0.6 \%$ higher total mortality, with similar effects on cardiovascular mortality. ${ }^{43}$

Other studies chose to analyze the short-term cardiovascular effects of air pollution in terms of morbidity (i.e. ischemic heart disease, arrhythmias and heart failure). For instance, in a US population over 65 years of age hospital admissions due to heart failure showed a $1.28 \%$ increase in risk for each $10 \mu \mathrm{g} / \mathrm{m}^{3} \mathrm{PM}_{2.5}$ rise registered on the same day. ${ }^{44}$ Wellenius et al., ${ }^{45}$ who from 1986 to 1999 analyzed the association between PM air pollution and hospital admissions for heart failure in seven US cities, found that a $10 \mu \mathrm{g} / \mathrm{m}^{3}$ rise in $\mathrm{PM}_{10}$ was accompanied by a $0.7 \%$ increase on the same day in the rate of admissions. In the framework of the Intermountain Heart Collaborative Study (IHCS), a $10 \mu \mathrm{g} / \mathrm{m}^{3}$ increase in short-term exposure to fine PM was associated with a $4.5 \%$ increase in the risk of acute coronary events. ${ }^{46}$ The association between traffic-related air pollution and acute myocardial infarction is also supported by the European Health Effects of Air Pollution among Susceptible Subpopulations (HEAPSS) study. ${ }^{47}$ Two more recent multicenter studies conducted in cities in the Mediterranean area, the EpiAir2 and the MED-PARTICLES, ${ }^{48,49}$ found a positive association between PM size fractions and cardiovascular hospital admissions.

Globalization and economic growth have extended the problems of the adverse health effects of air pollution to middle- and low-income countries, where rapid industrialization and increasing urbanization are associated with a huge increase in demands for energy, produced mainly from the combustion of coal and other solid fuels. Studies
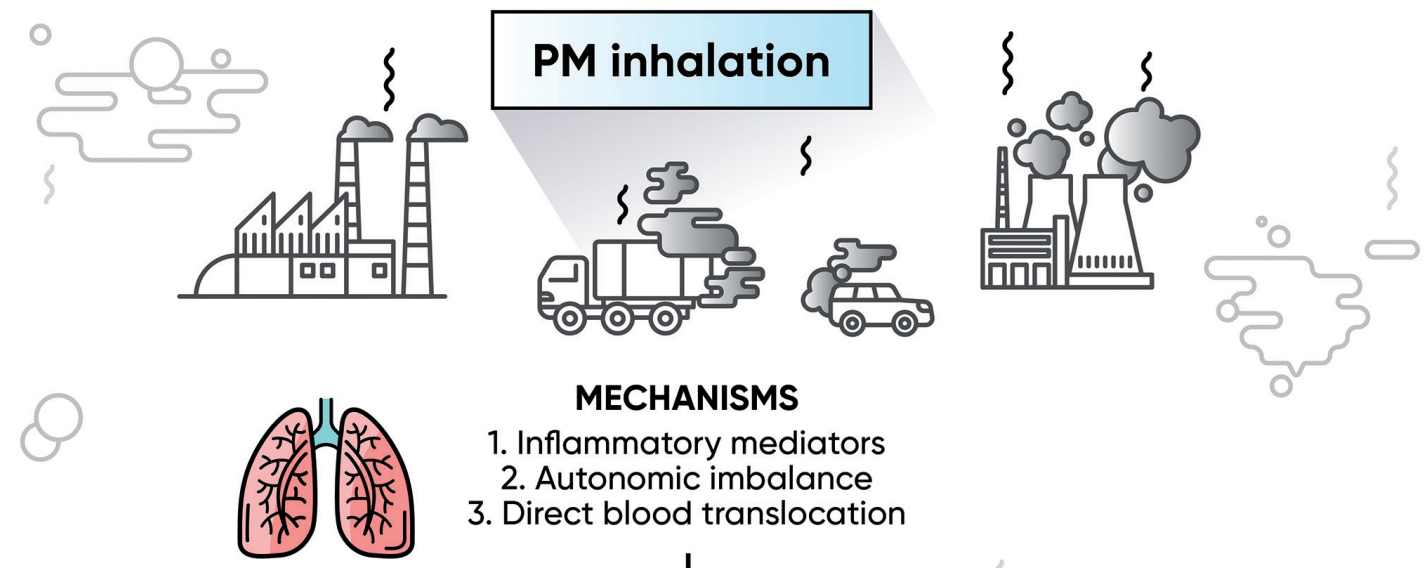

1. Inflammatory mediators

2. Autonomic imbalance

3. Direct blood translocation
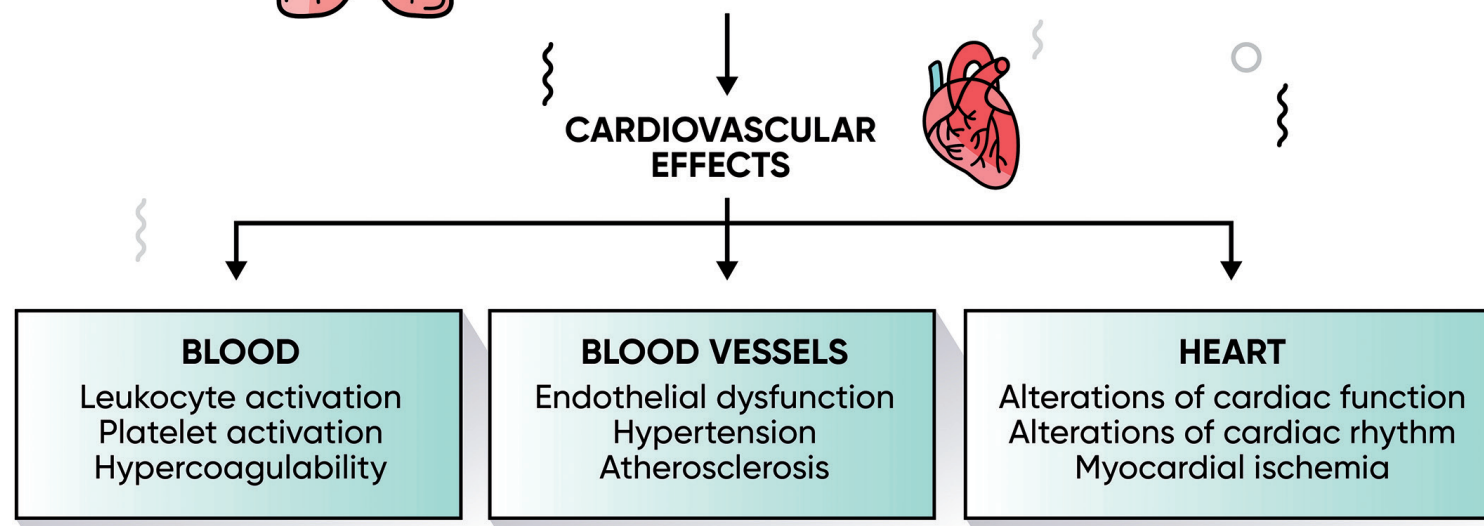

Figure 1. Main pathogenic mechanisms of the inhalation of particulate matter (PM) on cardiovascular disease. 
carried out in China documented that there, in the highly polluted urban areas, there was a positive association between PM exposure and coronary artery disease morbidity and mortality. ${ }^{50,51}$ However, the observed effects on health were surprisingly smaller in magnitude per amount of pollution exposure than the corresponding effects in less polluted areas of the Western countries, even though the population-attributable risk fraction is greater in China due to its large population density. ${ }^{52}$

With regards to air pollution and cerebrovascular diseases, a study from South Korea demonstrated an association with stroke mortality. ${ }^{53}$ In nine US cities, Wallenius et al..$^{54}$ observed that, in people aged 65 years or over, an acute $\mathrm{PM}_{10}$ increase of $22 \mu \mathrm{g} / \mathrm{m}^{3}$ was associated with a $1.03 \%$ higher rate of hospital admissions for ischemic stroke. Across 204 US counties, Dominici et al. ${ }^{44}$ reported a $0.81 \%$ increase in hospital admissions due to ischemic cerebrovascular disease per $10 \mu \mathrm{g} / \mathrm{m}^{3}$ increment of $\mathrm{PM}_{2.5}$ on the same day. Other studies in North America and Europe confirmed the association between increased hospital admissions for stroke and elevations of coarse, fine and ultra-fine PM..$^{5,4,56}$ Finally, a time-series analysis conducted from 2000 to 2006 in 75 US cities estimated a $1.03 \%$ increase in deaths for CVD, a $1.22 \%$ increase for myocardial infarction, and a $1.76 \%$ increase for stroke..$^{57}$

Considering the huge amount of published clinical data on the cardiovascular adverse effects of PM ambient air pollution, several systematic reviews have attempted to summarize these data by performing quantitative analyses of pooled data..$^{58 \cdot 76}$ We report their main results in Table 1. These confirm that there is a strong association between exposure to periods of high air pollution and cardiovascular morbidity and mortality. ${ }^{58-60,02-68,70-74}$

\section{Long-term effects}

In addition to the short-term effects of relatively shortlasting peaks of exposure to air pollution, there is also robust evidence that annual exposure or exposure over several years increases the risk of cardiovascular morbidity and mortality. ${ }^{6}$ The large Harvard Six Cities Study (HSCS) was the first to document an association between air pollution and increased general and cardiopulmonary mortality, by means of a 14- to 16-year survival analysis of a population of approximately 8,000 US citizens. ${ }^{77}$ The extended follow up of the HSCS showed that the relative risk ratio of cardiovascular mortality increased by 1.28 for a $10 \mu \mathrm{g} / \mathrm{m}^{3}$ rise in $\mathrm{PM}_{2.5}{ }^{78}$ Positive associations between long-term exposure to air pollutants and all-cause and cardiovascular mortality were confirmed in other prospective studies in the framework of large cohorts from the general population. ${ }^{6}$ For example, the American Cancer Society (ACS) conducted a study between 1982 and 1989. They linked local ambient air quality to the individual risks of more than 500,000 residents from approximately 150 US cities. They found a 1.17 risk ratio for all-cause mortality in association with increased levels of $\mathrm{PM}_{2.5 .}{ }^{79}$ The extended 16-year follow up of the ACS study demonstrated that for each $10 \mu \mathrm{g} / \mathrm{m}^{3}$ rise in the mean annual $\mathrm{PM}_{2.5}$ concentration there was a $6 \%$ increased risk of cardiopulmonary deaths ${ }^{80}$ In addition, the multicenter European Study of Cohorts for Air Pollution Effects (ESCAPE) found an increased hazard ratio (HR) of 1.07 for all-cause mortality for a $5 \mu \mathrm{g} / \mathrm{m}^{3}$ rise in $\mathrm{PM}_{2.5}{ }^{8}{ }^{81}$ Sub-analyses from the ESCAPE cohort showed an association between long-term $\mathrm{PM}_{2.5}$ exposure and the risk of acute coronary events and stroke
(HR: 1.13 and 1.40 for a $5 \mu \mathrm{g} / \mathrm{m}^{3}$ rise in $\left.\mathrm{PM}_{2.5}\right)^{\text {82,83 }}$ More recently, a prospective cohort study from the Netherlands demonstrated that the long-term exposure to ultrafine particles was associated with an increased risk for all incident CVD (HR: 1.18, 95\%CI: 1.03-1.34), myocardial infarction (HR: 1.34, 95\%CI: 1.00-1.79) and heart failure (HR: 1.76, $95 \%$ CI: $1.17-2.66) .{ }^{84}$ The impact on the cardiovascular system of long-term exposure to air was also observed in a study from Hong Kong, which demonstrated that, for 10$\mu \mathrm{g} / \mathrm{m}^{3} \mathrm{PM}_{2.5}$ the increase in the mortality HR of residents was 1.22 (95\%CI: 1.08-1.39) for cardiovascular causes, 1.42 (95\% CI: 1.16-1.73) for ischemic heart disease, and 1.24 (95\%CI: 1.00-1.53) for cerebrovascular disease. ${ }^{85}$ Taken together, these studies provide unequivocal evidence of the positive association between prolonged exposure to particulate air pollution and adverse cardiovascular events. ${ }^{61,72,75,76}$

\section{Air pollution and venous thromboembolism}

Less is known about the association between air pollution exposure and venous thromboembolism (VTE), the third most frequent CVD. ${ }^{86}$ Dales et al. ${ }^{87}$ reported a shortterm increase in hospital admissions for venous thrombosis and pulmonary embolism in Santiago, Chile, that was proportional to the concentration of particulate and gaseous air pollutants. In Italy, the elevation of coarse (but not finer) PM was associated with more admission rates to the emergency room for venous thromboembolism. ${ }^{88}$ While some studies documented the long-term association of airborne pollution and deep vein thrombosis ${ }^{89}$ others found no link, ${ }^{90}$ making the relationship between VTE and PM exposure still to be determined. Some indirect evidence corroborating a positive association comes from a systematic review and meta-analysis by Dentali et al. ${ }^{91}$ who observed that VTE had a significantly higher incidence in winter; a finding that matched the parallel seasonal increase in PM. Thus, more studies are needed to clarify whether or not there is a short- and long-term association between air pollution and VTE, a concept that is biologically plausible given the systemic hypercoagulable state in both conditions.

\section{Recent striking findings}

Until recently, the $\mathrm{WHO}$ and the GBD (i.e. the two main sources of data on global mortality, morbidity and disability) were in close agreement on a figure of approximately four million deaths attributed to ambient $\mathrm{PM}_{2.5}$; deaths that could be avoided. Both sources also agreed that CVD is the main cause of death attributed to $\mathrm{PM}_{2.5}$. However, in 2018 and 2019, two studies did estimate a much greater mortality and morbidity burden, both globally and in Europe. These studies used a new and more accurate hazard ratio function of $\mathrm{PM}_{2.5}$ concentrationresponse. The Global Exposure Mortality Model (GEMM) has a number of advantages over the Integrated Exposure Response (IER) function employed by both the WHO and the GBD. It is based on individual concentration-response data stemming exclusively from exposure to ambient air $\mathrm{PM}_{2.5}$, thereby avoiding sources other than the ambient air that were additional components of the IER (household air, active and passive cigarette smoking). Furthermore, the GEMM was developed by Burnett and 50 other authors ${ }^{8}$ from the analysis of much larger and more geographically extended individual data, obtained from the $\mathrm{PM}_{2.5}$ concentration-response in 41 cohorts from 16 coun- 
Table 1. Results of recent systematic reviews and meta-analyses of the short- and long-term association between particulate matter air pollution and cardiovascular diseases.

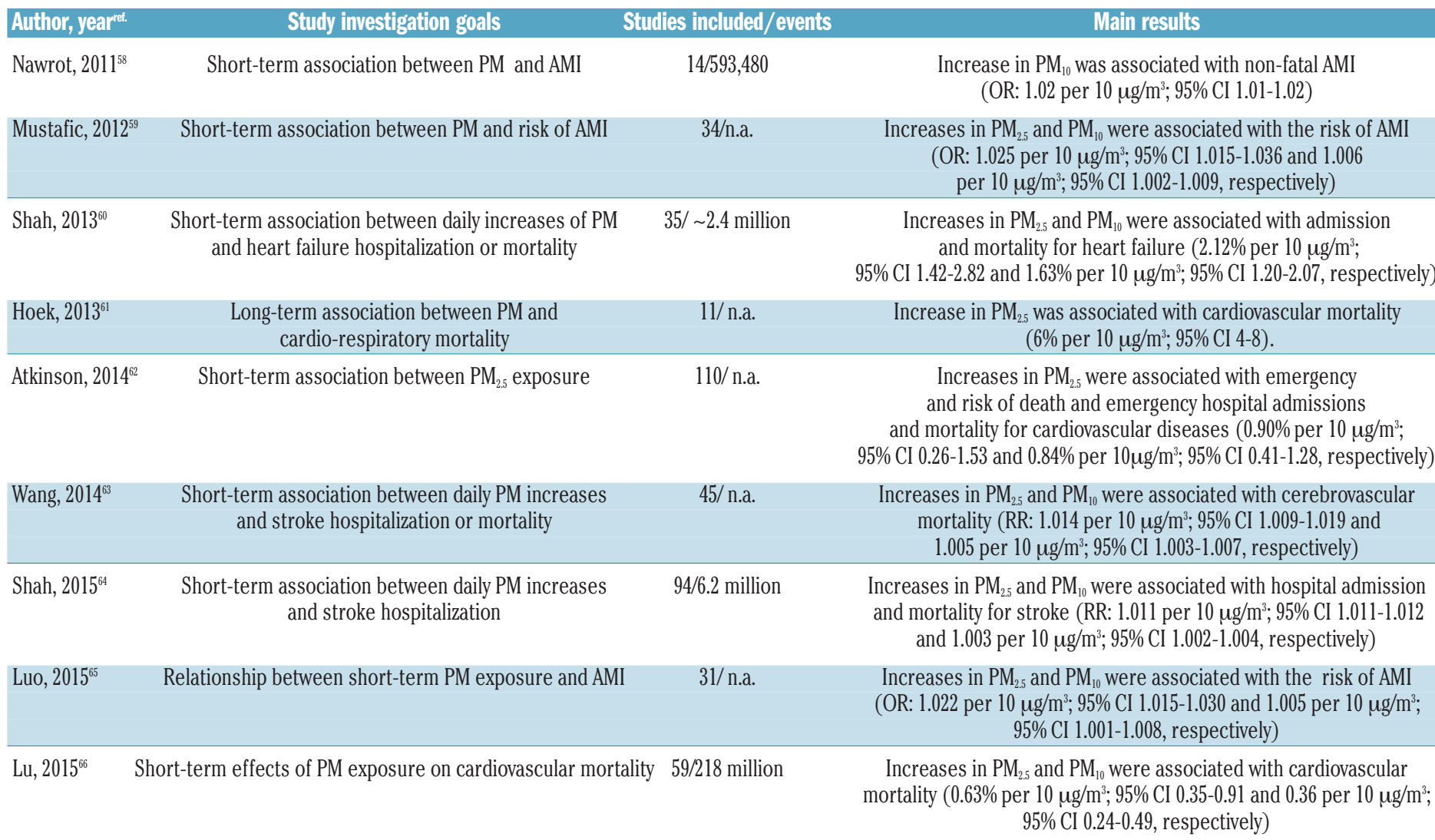

$\begin{array}{cc}\text { Cai, } 2016^{67} & \begin{array}{c}\text { Short-term association between PM levels and } \\ \text { hospitalization or mortality for AMI }\end{array} \quad 25 / \text { n.a. }\end{array}$

Increases in $\mathrm{PM}_{25}$ were associated with the risk of hospitalization and mortality for AMI (RR: 1.024 per $10 \mu \mathrm{g} / \mathrm{m}^{3}$;

95\% CI 1.007-1.041 and 1.012 per $10 \mu \mathrm{g} / \mathrm{m}^{3} ; 95 \%$ CI 1.010-1.015,

respectively). Increases in $\mathrm{PM}_{10}$ were associated with risk of hospitalization and mortality for AMI (OR: 1.011 per $10 \mu \mathrm{g} / \mathrm{m}^{3}$; $95 \%$ CI 1.006-1.016 and 1.008 per $10 \mu \mathrm{g} / \mathrm{m}^{3} ; 95 \%$ CI 1.004-1.012, respectively)

Song, 2016 $\quad$ Short-term association between PM and arrhythmia $\quad$ 23/2 million hospitalization or mortality

Arrhythmia hospitalization or mortality were associated with increases in $\mathrm{PM}_{2.5}$ (RR: 1.015 per $10 \mu \mathrm{g} / \mathrm{m}^{3} ; 95 \%$ CI 1.006-1.024) and $\mathrm{PM}_{10}$ (RR: 1.009 per $10 \mu \mathrm{g} / \mathrm{m}^{3} ; 95 \%$ CI 1.004-1.014)

Tang, 2016 $\quad$ Association between PM and venous thrombosis $\quad 8 / 700,000$

No association between PM exposure and venous thrombosis

Shao, $201670 \quad$ Short-term association between PM and development $\quad 4 / 461,441$ of atrial fibrillation

Increase in $\mathrm{PM}_{2.5}$ was associated with atrial fibrillation development

$\begin{array}{ll}\text { of atrial fibrillation } & \text { (RR: } 1.009 \mathrm{per} 10 \mu \mathrm{g} / \mathrm{m}^{3} ; 95 \% \mathrm{Cl} 1.002-1.016 \text { ). }\end{array}$

\begin{tabular}{|c|c|c|}
\hline Achilleos, $2017^{71}$ & Short-term effects of PM on mortality & $\begin{array}{c}\text { A } 10 \mu \mathrm{g} / \mathrm{m}^{3} \text { of } \mathrm{PM}_{2.5} \text { increase was associated with a } 0.80 \% \\
(95 \% \mathrm{Cl} 0.41-1.20) \text { increase in cardiovascular mortality }\end{array}$ \\
\hline
\end{tabular}

Newell, 2017 $\quad$ Short-term and long-term cardiovascular effects

85/- $\quad$ Increases in same-day $\mathrm{PM}_{2.5}$ and $\mathrm{PM}_{10}$ were associated with of PM in low- and middle-income countries

cardiovascular mortality ( $0.47 \%$ per $10 \mu \mathrm{g} / \mathrm{m}^{3} ; 95 \% \mathrm{CI} 0.34-0.61$ and 0.27 per $10 \mu \mathrm{g} / \mathrm{m}^{3} ; 95 \%$ CI $0.11-0.44$, respectively)

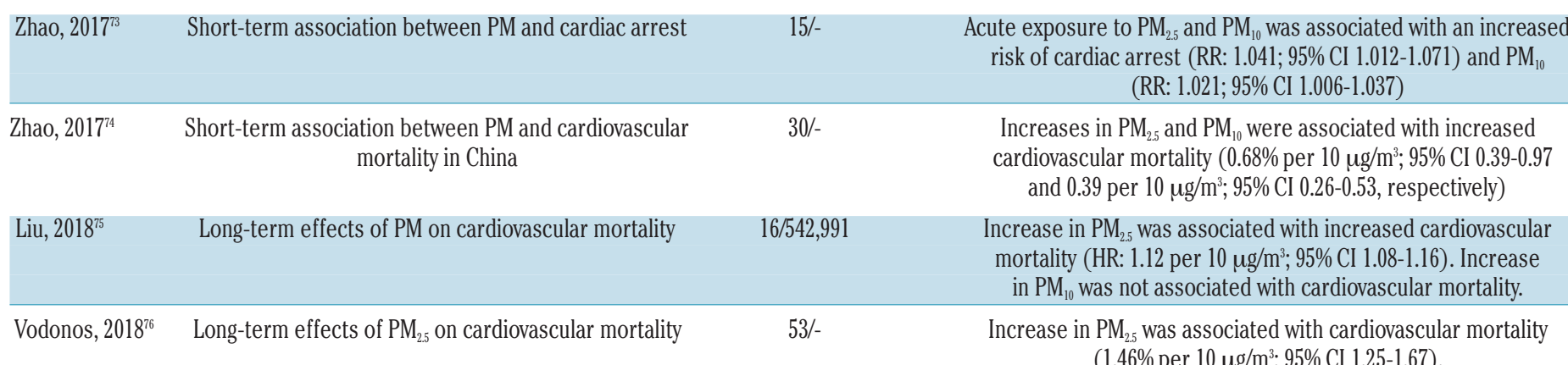

AMI: acute myocardial infarction; n.a.: not available; RR: relative risk; PM: particulate matter; OR: odds ratio; HR: hazard ratio.

$\left(1.46 \%\right.$ per $10 \mu \mathrm{g} / \mathrm{m}^{3} ; 95 \%$ CI 1.25-1.67). 
tries, involving 20,000 cases and 2.5 million deaths, also including a highly polluted and densely populated country such as China, whereas the WHO-GBD IER was mainly based on the less polluted Western Europe, Canada, and USA. In addition, the IER function had been applied only to five main causes of mortality (coronary artery disease, cerebrovascular disease, chronic obstructive pulmonary disease, lung cancer, and lower respiratory tract illness), whereas the study of Burnett et al. ${ }^{8}$ developed and applied GEMM to the whole world, using mortality data from non-communicable diseases plus pneumonia. They attributed 8.9 million annual deaths to the exposure to ambient air $\mathrm{PM}_{2.5}$, more than twice those attributed by the WHO and the GBD. Applying the GEMM function to Europe, Lelieveld et al. ${ }^{92}$ reported that the number of $\mathrm{PM}_{2.5}$ - related deaths was as high as 790,000 per year for the whole continent, so that the excess mortality attributable to $\mathrm{PM}_{2.5}$ was more than double the previous GBD estimate $(269,000)$. When the all-cause annual deaths attributed to $\mathrm{PM}_{2.5}$ were calculated for the five most populated European countries and normalized for the number of inhabitants, the highest prevalence of annual premature deaths per 100,000 were recorded in Germany (154), followed by Poland (150), Italy (136), France (105), and the UK (98). Lelieveld et al..$^{92}$ have also evaluated the avoidable deaths attributed to each disease and found once more that the major fraction of mortality was due to CVD, with a much higher burden for coronary artery disease than for cerebrovascular disease, COPD, lung cancer and pneumonia. A large additional fraction of excess mortality was due to other non-communicable diseases as yet not accurately specified, but arguably associated to CVD, such as hypertension and diabetes. Finally, Lelieveld et al. estimated that, in Europeans, $\mathrm{PM}_{2.5}$ air pollution decreases the mean life expectancy by 2.2 years. ${ }^{92}$

These new findings are striking, indicating as they do that the burden of mortality and, in particular cardiovascular mortality, globally as well as in Europe, is much greater than appreciated so far. They provide real, clear support to the statement made by the European Court of Auditors, an institution that has the task of implementing the recommendations issued by the European Union: "European citizens still breathe harmful air, mainly due to weak legislation and poor policy implementation" (https://www.eca.europa.eu/en/Pages/AuditReportsOpini ons.aspx). The allusion to weak legislation and policy implementation is likely to be an indirect criticism to the European Union, that still provides ambient air quality (AAQ) directives that are much less stringent for health preservation than the air quality guidelines (AOG) of the WHO (Table 2), which are in turn close to those adopted in the USA by the Environment Protection Agency (EPA). All in all, these new findings provide striking and real evidence to a public statement made by Janez Potocnik, the European Commissioner for the Environment from 20102014: "If you think the economy is more important than the environment, try holding your breath while counting your money" [http://europa.eu/rapid/pressrelease_SPEECH-13-822_en.htm].

\section{Open issues and research needs}

The dramatic dimension of the dire effects on health of air pollution, and particularly of $\mathrm{PM}_{2.5}$, demands more research efforts in order to better understand the pathogenic mechanisms and thus to develop improved weapons
Table 2. Comparison of the ceilings of mean annual concentrations (in $\mu \mathrm{g} / \mathrm{mm}^{3}$ ) of the main air pollutants according to the current directives for ambient air quality of the European Union (EU) and to the air quality guidelines of the World Health Organization (WHO).

\begin{tabular}{lcc} 
Pollutant & EU & WhO \\
$\mathrm{PM}_{10}$ & 40 & 20 \\
$\mathrm{PM} 2.5$ & 25 & 10 \\
\hline Nitrogen dioxide & 40 & 40 \\
Ozone & 120 & 100 \\
\hline
\end{tabular}

for primary and secondary prevention, not only of CVD, but also of other very frequent non-communicable diseases such as cancer and respiratory diseases. Furthermore, more and more evidence is accumulating that air pollution has noxious effects on the central nervous system (CNS) through chronic neuroinflammation, neuronal and myelin damage that lead to degenerative neurological diseases and cognitive deficits. There is also a need for more research and knowledge on the growing data showing air pollution impairs the development of the child's brain, affecting attention functions, memory, functional integration, and inhibition control mechanisms. More information is needed on the differential vulnerability of subgroups such as children and pregnant women, the elderly, financially deprived people, and outdoor workers. Furthermore, experimental and epidemiological studies should address the still open and cogent issue of the role of each component of air pollution, with particular emphasis on the chemical components and physical characteristics of PM. There is preliminary evidence that some chemical constituents may be more dangerous than others, such as organic matter, black carbon and nitrates. Other studies have emphasized the risk associated with metals such as vanadium and nickel. ${ }^{93}$ Furthermore, it is still poorly understood whether or not the different origins of PM (i.e. primary or secondary; natural or anthropogenic; from traffic, heating or industry; agriculture or animal farms) have different potencies in causing the adverse effects of PM on health. Therefore, for air quality mitigation policies it is important to consider the interaction between the composition and origin of the local polluttome and the epidemiological characteristics of the populations concerned. ${ }^{94}$

Research should also focus on the more extensive measurement and the clinical effects of ultrafine particles, since, owing to the fact that they have a diameter of less than 100 nanometers, these are potentially more damaging than larger particles. However, available experimental and epidemiological evidence is limited. ${ }^{95}$ Finally, an important area of research would be to clarify the relationship between medication intake and air pollution. Conti et al. ${ }^{90}$ have shown a positive association between $\mathrm{PM}_{10}$ and the level of prescription of cardiorespiratory drugs. They took this to be an indication of cardiovascular and pulmonary events triggered by peaks in air pollution. In this context, it would also be of interest to evaluate whether or not the long-term intake of widely and chronically prescribed medications such as statins, aspirin and $\beta$-blockers is associated with less cardiovascular events, in comparison with individuals not taking these drugs and equally exposed to high pollution levels. 


\section{Conclusions}

An array of experimental and epidemiological studies have strengthened our general knowledge on the robust association between air pollution and cardiovascular morbidity and mortality. Causal interpretation of the exposure-outcome association is supported not only by the impressive consistence and concordance of so many findings obtained in different countries and contexts, but also by studies showing that the improvement in air quality is associated with a number of public health benefits, including clinically relevant outcomes such as lower mortality, ${ }^{78}$ longer life expectancy, ${ }^{97}$ and better lung function..$^{98}$ Considering the deleterious effects on the cardiovascular system of air pollution and the increasing socio-economic burden of the direct and indirect costs of related diseases, a number of countries, especially those with better economies, have implemented initiatives that have indeed, in some of them, managed to reduce the burden of air pollution. In spite of this, as recently as 2018 , the WHO issued a press release stating that half of the world's population is still exposed to increasing levels of air pollution (www.who.int//newsroomdetails). This gloomy situation is epitomized by the fact that the more stringent Air Quality Guidelines set out by the WHO for health preservation (Table 2) are far from being met, particularly in the urban areas not only of rapidly developing countries such as China and India, but even in Europe. Furthermore, there is emerging evidence that even $\mathrm{PM}_{2.5}$ concentrations below the ceiling values of the $\mathrm{WHO}$ air quality guidelines are associated with important morbidity and mortality figures, ${ }^{99,100}$ indicating that, even in the most successful countries, further efforts to reduce ambient air pollution are warranted in order to obtain more substantial health benefits for citizens.

So, how to tackle the formidable battle against air pollution? A call for action has been made by the United Nations Sustainable Development Goals (SDG), and one of these is particularly clear: "Make cities and human settlements inclusive, safe, resilient and sustainable" (SGD 11). Replacing fossil fuels with renewable energy and achieving carbon net zero is as obvious as it is difficult, together with actions aimed at renewing transport fleets with zero emission vehicles or by fitting them with more effective filters and combustion engines until electric vehicles can come into use. In addition, we must recognize that human nutrition and the use of food from animal sources are important contributors to air pollution through ammonia produced by extensive agriculture and animal farming that is released into the air from stables, manure storage and application procedures, with the added contribution from food disposal. Even though the authors of this article believe that fighting air pollution and climate changes are part of the duties and responsibility of healthcare professionals, we do not have a magic wand. We are also convinced that one of the best approaches is to foster efforts towards promoting a 'green' living and working environment. ${ }^{101}$ Very recent satellite data show increasing areas of vegetation in parts of the world, and that this 'greening' pattern is particularly prominent in highly polluted and urbanized countries such as China and India, in contrast to countries such as Brazil and Indonesia. The two Asian subcontinents are actively developing mitigation programs tailored to expand cropland and forests, with the goal of tackling two huge and interconnected problems at the same time: i.e. air pollution and global warming. ${ }^{102}$

\section{References}

1. GBD 2017 DALYs and HALE Collaborators. Global, regional, and national disabilityadjusted life-years (DALYs) for 359 diseases and injuries and healthy life expectancy (HALE) for 195 countries and territories, 1990-2017: a systematic analysis for the Global Burden of Disease Study 2017. Lancet. 2018;392(10159):1859-1922.

2. OECD. Health at a glance 2017: OECD Indicators. Published on November 102017. Available

http://www.oecd.org/health/health-at-aglance-19991312.htm

3. WHO -World Health OrganizationAmbient Air Pollution: A global assessment of exposure and burden of disease. Available online at: https://www.who.int/phe/publications/air-pollution-global-assessment/en/ Accessed 28 March 2019.

4. WHO. Ambient and household air pollution and health. Available online at: http://who.int/phe/health_topics/outdoorair/databases/en/ Accessed 28 march 2019.

5. Franchini M, Mannucci PM, Harari S, Pontoni F, Croci E. The health and economic burden of air pollution. Am J Med. 2015;128(9):931-932.

6. Franchini M, Mannucci PM. Thrombogenicity and cardiovascular effects of ambient air pollution. Blood. 2011;118(9): 2405-2412.
7. Miller MR, Shaw CA, Langrish JP. From particles to patients: oxidative stress and the cardiovascular effects of air pollution. Future Cardiol. 2012;8(4):577-602.

8. Burnett R, Chen H, Szyszkowicz M, et al. Global estimates of mortality associated with long-term exposure to outdoor fine particulate matter. Proc Natl Acad Sci U S A. 2018;115(38):9592-9597.

9. Thurston GD, Kipen H, Annesi-Maesano I, et al. A joint ERS/ATS policy statement: what constitutes an adverse health effect of air pollution? An analytical framework. Eur Respir J. 2017;49(1)

10. Franchini M, Guida A, Tufano A, Coppola A. Air pollution, vascular disease and thrombosis: linking clinical data and pathogenic mechanisms. J Thromb Haemost. 2012;10(12):2438-2451.

11. Rajagopalan S, Al-Kindi SG, Brook RD. Air pollution and cardiovascular disease: JACC State-of-the-Art Review. J Am Coll Cardiol. 2018;72(17):2054-2070.

12. GBD 2017 Risk Factor Collaborators. Global, regional, and national comparative risk assessment of 84 behavioural, environmental and occupational, and metabolic risks or clusters of risks for 195 countries and territories, 1990-2017: a systematic analysis for the Global Burden of Disease Study 2017. Lancet. 2018;392(10159):19231994.

13. Bathnagar A. Enviromental Cardiology.
Studying mechanistic links between pollution and heart disease. Cir Res. 2006;99(7):692-705.

14. Robertson S, Miller MR. Ambient air pollution and thrombosis. Part Fibre Toxicol. 2018;15(1):1.

15. Gurgueira S.A, Lawrence J, Coull B, Murthy GGK, Gonzalez-Flecha B. Rapid increase in the steady-state concentration of reactive oxygen species in the lungs and heart after particulate air pollution inhalation. Environ Health Perspect. 2002;110(8):749-755.

16. Peters A, Frohlich M, Doring A, et al. Particulate air pollution is associated with an acute phase response in men. Eur Heart J. 2001;22(14):1198-1204.

17. Donaldson K, Mills N, MacNee W, Robinson S, Newby D. Role of inflammation in cardiopulmonary health effects of PM. Toxicol Appl Pharmacol. 2005;207(2 Suppl):483-488.

18. Ruckerl R, Phipps RP, Schneider A, et al. Ultrafine particles and platelet activation in patients with coronary heart disease results from a prospective panel study. Part Fibre Toxicol. 2007;4:1.

19. Ruckerl R, Ibald-Mulli A, Koenig W, et al. Air pollution and markers of inflammation and coagulation in patients with coronary heart disease. Am J Respire Care Med. 2006;173(4):432-441.

20. Baccarelli A, Zanobetti A, Martinelli I, et al Effects of exposure to air pollution on blood 
coagulation. J Thromb Haemost. 2007;5(2): 252-260.

21. Bonzini M, Tripodi A, Artoni A, et al. Effects of inhalable particulate matter on blood coagulation. J Thromb Haemost. 2010;8(4): 662-668.

22. Watkinson WP, Campen MJ, Costa DL. Cardiac arrhythmia after exposure to residual oil fly ash particles in a rodent model of pulmonary hypertension. Toxicol Sci. 1998;41(2):209-216.

23. Campen MJ, Costa DL, Watkinson WP. Cardiac and thermoregulatory toxicity of residual oil fly ash in cardiopulmonary-compromised rats. Inhal Toxicol. 2000;12 Suppl 2:7-22

24. Pope CA, Verrier RL, Lovett EG, et al. Heart rate variability associated with particulate air pollution. Am Heart J. 1999;138(5 Pt 1):890-899

25. Gold DR, Litonjua A, Schwartz J, et al. Ambient pollution and heart rate variability. Circulation. 2000;101(11):1267-1273

26. Peters A, Liu E, Verrier RL, et al. Air pollution and incidence of cardiac arrhythmia. Epidemiology. 2000;11(1):11-17.

27. Ibald-Mulli A, Stieber J, Wichmann HE, et al. Effects of air pollution on blood pressure: a population-based approach. Am J Pub Health. 2001;91(4):571-577.

28. Urch B, Silverman F, Corey P, et al. Acute blood pressure responses in healthy adults during controlled air pollution exposures. Environ Health Perspect. 2005;113(8):105255.

29. Bhatnagar A. Environmental cardiology: studying mechanistic links between pollution and heart disease. Circ Res. 2006;99(7):692-705.

30. Sander M, Chavoshan B, Victor RG. A large blood pressure-raising effect of nitric oxide synthase inhibition in humans. Hypertension. 1999;33(4):937-942.

31. Suwa T, Hogg JC, Quinlan KB, Ohgami A, Vincent R, van Eeden SF. Particulate air pollution induces progression of atherosclerosis. J Am Coll Cardiol. 2002;39(6):935-942.

32. Sun $\mathrm{Q}$, Wang $\mathrm{A}$, Jin $X$, et al. Long-term air pollution exposure and acceleration of atherosclerosis and vascular inflammation in an animal model. JAMA. 2005;294(23):30033010.

33. Kunzli N, Jerrett M, Mack WJ, et al. Ambient air pollution and atherosclerosis in Los Angeles. Environ. Health Perspect. 2005;113(2):201-206.

34. Hoffmann B, Moebus S, Mohlenkamp S, et al. Residential exposure to traffic is associated with coronary atherosclerosis. Circulation. 2007;116(5):489-496.

35. Li H, Cai J, Chen R, Zhao Z, et al. Particulate matter exposure and stress hormone levels: a randomized, double-blind, crossover trial of air purification. Circulation. 2017;136(7): 618-627.

36. Mills NL, Donaldson K, hadoke PW. Adverse cardiovascular effects of air pollution. Nature Clin Pract. 2009;6(1):36-44

37. Münzel T, Gori T, Al-Kindi S, et al. Effects of gaseous and solid constituents of air pollution on endothelial function. Eur Heart J. 2018;39(38):3543-3550.

38. Logan WP. Mortality in the London fog incident, 1952. Lancet. 1953;1(6755):336-338.

39. Hamanaka RB, Mutlu GM. Particulate matter air pollution: effects on the cardiovascular system. Front Endocrinol. 2018;9:680

40. Samet JM, Dominici F, Curriero FC, Coursac I, Zeger SL. Fine particulate air pollution and mortality in 20 U.S. cities, 1987-1994. N Engl J Med. 2000;343(24):1742-1749.
41. Analitis A, Katsouyanni K, Dimakopoulou $\mathrm{K}$, et al. Short-term effects of ambient particles on cardiovascular and respiratory mortality. Epidemiology. 2006;17(2):230-233.

42. Biggeri A, Bellini O, Terracini B. Meta-analysis of the Italian studies on short-term effects of air pollution MISA 1996-2002. Epidemiol Prev. 2004;28(4-5 Suppl):4-100.

43. Samoli E, Peng R, Ramsay T, et al. Acute effects of ambient particulate matter on mortality in Europe and North America: results from the APHENA study. Environ Health Perspect. 2008;116(11):1480-1486.

44. Dominici F, Peng RD, Bell ML, et al. Fine particulate air pollution and hospital admission for cardiovascular and respiratory diseases. JAMA. 2006;295(10):1127-1134

45. Wellenius GA, Schwartz J, Mittleman MA Particulate air pollution and hospital admissions for congestive heart failure in seven United States cities. Am J Cardiol. 2006:97:404-408.

46. Pope CA III, Muhlestein JB, May HT, Renlund DG, Anderson JL, Horne BD Ischemic heart disease events triggered by short-term exposure to fine particulate air pollution. Circulation. 2006;114(23):24432448.

47. Lanki T, Pekkanen J, Aalto P, et al. Associations of traffic related air pollutants with hospitalisation for first acute myocardial infarction: the HEAPSS study. Occup Environ Med. 2006;63(12):844-851.

48. Scarinzi C, Alessandrini ER, Chiusolo M, et al. Air pollution and urgent hospital admissions in 25 Italian cities: results from the EpiAir2 project. Epidemiol Prev. 2013;37(45):230-241

49. Stafoggia M, Samoli E, Alessandrini E,et al. Short-term associations between fine and coarse particulate matter and hospitalizations in Southern Europe: results from the MED-PARTICLES project. Environ Health Perspect. 2013;12(9):1026-1033

50. Xie W, Li G, Zhao D, et al. Relationship between fine particulate air pollution and ischemic heart disease morbidity and mortality. Heart. 2015;101(4):257-263

51. Xu A, Mu Z, Jiang B, et al. Acute effects of particulate air pollution on ischemic heart disease hospitalizations in Shanghai, China. Int J Environ Res Public Health. 2017;14(2).

52. Li T, Zhang Y, Wang J, et al. All-cause mortality risk associated with long-term exposure to ambient PM2.5 in China: a cohort study. Lancet Public Health. 2018;3(10):e470-e477.

53. Hong YC, Lee JT, Kim H, Ha EH, Schwartz J, Christiani DC. Effects of air pollutants on acute stroke mortality. Environ Health Perspect. 2002;110(2):187-191.

54. Wellenius GA, Schwartz J, Mittleman MA. Air pollution and hospital admissions for ischemic and hemorrhagic stroke among medicare beneficiaries. Stroke. 2005;36(12):2549-2553.

55. Andersen ZJ, Olsen TS, Andersen KK, Loft S, Ketzel M, Raaschou-Nielsen O. Association between short-term exposure to ultrafine particles and hospital admissions for stroke in Copenhagen, Denmark. Eur Heart J. 2010;31(16):2034-2040.

56. Low RB, Bielory L, Qureshi AI, Dunn V, Stuhlmiller DF, Dickey DA. The relation of stroke admissions to recent weather, airborne allergens, air pollution, seasons, upper respiratory infections, and asthma incidence, September 11, 2001, and day of the week. Stroke. 2006:37(4):951-957.

57. Dai L, Zanobetti A, Koutrakis P, Schwartz JD. Associations of fine particulate matter species with mortality in the United States: a multicity time-series analysis. Environ Health Perspect. 2014;122(8):837-842.

58. Nawrot TS, Perez L, Kunzli N, Munters E, Nemery B. Public health importance of triggers of myocardial infarction: a comparative risk assessment. Lancet. 2011;377(9767): 732-740.

59. Mustafic H, Jabre P, Caussin C, et al. Main air pollutants and myocardial : a systematic review and meta-analysis. JAMA. 2012;307(7):713-721.

60. Shah AS, Langrish JP, Nair H, et al. Global association of air pollution and heart failure: a systematic review and meta-analysis. Lancet. 2013;382(9897):1039-1048.

61. Hoek G, Krishnan RM, Beelen R, et al. Longterm air pollution exposure and cardio-respiratory mortality: a review. Environ Health. 2013;12(1):43

62. Atkinson RW, Kang S, Anderson HR, Mills IC, Walton HA. Epidemiological time series studies of PM2.5 and daily mortality and hospital admissions: a systematic review and meta-analysis. Thorax. 2014;69(7):660665

63. Wang Y, Eliot MN, Wellenius GA. Shortterm changes in ambient particulate matter and risk of stroke: a systematic review and meta-analysis. J Am Heart Assoc. 2014;3(4); e000983.

64. Shah AS, Lee KK, McAllister DA, et al. Short term exposure to air pollution and stroke: systematic review and meta-analysis. BMJ. 2015;350:h1295.

65. Luo C; Zhu X, Yao C, et al. Short-term exposure to particulate air pollution and risk of myocardial infarction: a systematic review and meta-analysis. Environ Sci Pollut Res. 2015;22(19):14651-14662.

66. Lu F, Xu D, Cheng Y, et al. Systematic review and meta-analysis of the adverse health effects of ambient PM2.5 and PM10 pollution in the Chinese population. Environ Res. 2015;136:196-204.

67. Cai X, Li Z, Scott EM, Li X, Tang M. Shortterm effects of atmospheric particulate matter and myocardial infarction: a cumulative meta-analysis. Environ Sci Pollut Res. 2016;23(7):6139-6148

68. Song X, Liu Y, Hu Y, et al. Short-term exposure to air pollution and cardiac arrhythmia: a meta-analysis and systematic review. Int J Environ Res Public Health. 2016;13(7)

69. Tang L, Wang OI, Cheng ZP, Hu B, Liu JD, $\mathrm{Hu}$ Y. Air pollution and venous thrombosis: a meta-analysis. Sci Rep. 2016;6:32794.

70. Shao Q, Liu T, Korantzopoulos P, Zhang Z, Zhao J, Li G. Association between air pollution and development of atrial fibrillation: A meta-analysis of observational studies. Heart Lung. 2016;45(6):557-562

71. Achilleos S, Kioumourtzoglou MA, Wu CD Schwartz ID, Koutrakis P, Papatheodorou SI. Acute effects of fine particulate matter constituents on mortality: A systematic review and meta-regression analysis. Environ Int 2017;109:89-100

72. Newell K, Kartsonaki C, Lam KBH, Kurm OP. Cardiorespiratory health effects of particulate ambient air pollution exposure in low-income and middle-income countries: a systematic review and meta-analysis. Lancet Planet Health 2017;1(9):e368-e380.

73. Zhao R, Chen S, Wang W, et al. The impact of short-term exposure to air pollutants and the onset of out-of-hospital cardiac arrest: a systematic review and meta-analysis. Int J Cardiol. 2017:226:110-117.

74. Zhao L, Liang HR, Chen FY, Chen Z, Guan WJ, Li JH. Association between air pollution 
and cardiovascular mortality in China: a systematic review and meta-analysis. Oncotarget. 2017;8(39):66438-66448.

75. Liu Z, Wang F, Li W, et al. Does utilizing WHO's interim targets further reduce the risk -meta-analysis on ambient particulate matter pollution and mortality of cardiovascular diseases? Environ Poll. 2018;242(Pt B):1299-1307.

76. Vodonos A, Awad YA, Schwartz J. The concentration-response between long-term PM2.5 exposure and mortality; a metaregression approach. Environ Res. 2018;166:677-689.

77. Dockery DW, Pope CA 3rd, Xu X, et al. An association between air pollution and mortality in six U.S. cities. N Engl J Med. 1993;329(24):1753-1759.

78. Laden F, Schwartz J, Speizer FE, Dockery DW. Reduction in fine particulate air pollution and mortality: Extended follow-up of the Harvard Six Cities study. Am J Respir Crit Care Med. 2006;173(6):667-672.

79. Pope CA, Thun MJ, Namboodiri MM, et al. Particulate air pollution as a predictor of mortality in a prospective study of U.S. adults. Am J Respir Crit Care Med. 1995;151(3):669-674.

80. Pope CA 3rd, Burnett RT, Thun MJ, et al. Lung cancer, cardiopulmonary mortality, and long-term exposure to fine particulate air pollution. JAMA. 2002;287(9):1132-1141.

81. Beelen R, Raaschou-Nielsen O, Stafoggia M, et al. Effects of long-term exposure to air pollution on natural-cause mortality: an analysis of 22 European cohorts within the multicentre ESCAPE project. Lancet. 2014;383(9919):785-795.

82. Cesaroni G, Forastiere F, Stafoggia M, et al. Long term exposure to ambient air pollution and incidence of acute coronary events: prospective cohort study and meta-analysis in 11 European cohorts from the ESCAPE Project. BMJ. 2014;348:f7412.

83. Stafoggia M, Cesaroni G, Peters A, et al. Long-term exposure to ambient air pollution and incidence of cerebrovascular events: results from 11 European cohorts within the ESCAPE project. Environ Health Perspect. 2014;122(9):919-925

84. Downward GS, van Nunen EJHM, Kerckhoffs J, et al. Long-Term exposure to ultrafine particles and incidence of cardiovascular and cerebrovascular disease in a prospective study of a Dutch cohort. Environ Health Perspect. 2018;126(12): 127007.

85. Wong CM, Lai HK, Tsang H, et al. SatelliteBased Estimates of Long-Term Exposure to Fine Particles and Association with Mortality in Elderly Hong Kong Residents. Environ Health Perspect. 2015;123(11):1167 1172

86. Franchini $M$, Mengoli C, Cruciani $M$, Bonfanti C, Mannucci PM. Association between particulate air pollution and venous thromboembolism: A systematic literature review. Eur J Intern Med. 2016;27:10-13.

87. Dales RE, Cakmak S, Vidal B. Air pollution and hospitalization for venous thromboembolic disease in Chile. J Thromb Haemost. 2010;8(4):669-674.

88. Martinelli N, Girelli D, Cigolini D, et al. Access rate to the emergency department or venous thromboembolism in relationship with coarse and fine particulate matter air pollution. PLoS One. 2012;7:e34831.

89. Baccarelli A, Martinelli I, Pegoraro V, et al. Living near major traffic roads and risk of deep vein thrombosis. Circulation. 2009;119(24):3118-3124.

90. Kan H, Folsom AR, Cushman M, et al. Traffic exposure and incident venous thromboembolism in the atherosclerosis risk in communities (ARIC) study. J Thromb Haemost. 2011;9(4):672-678.

91. Dentali F, Ageno W, Rancan E, et al. Seasonal and monthly variability in the incidence of venous thromboembolism. A systematic review and a meta-analysis of the literature. Thromb Haemost. 2011;106(3):439-447.

92. Lelieveld J, KlingmullerK, Pozzer A, et al. Cardiovascular disease burden from ambient air pollution in Europe reassessed using novel hazard ratio functions. Eur Heart J. 2019;40(20):1590-1596.

93. Badaloni C, Cesaroni G, Cerza F, Davoli M, Brunekreef B, Forastiere F. Effects of longterm exposure to particulate matter and metal components on mortality in the Rome longitudinal study. Environ Int. 2017;109:146-154

94. Thurston G, Balmes J. We Need to "Think Different" about Particulate Matter. Am J Respir Crit Care Med. 2017;196(1):6-7.

95. Ohlwein S, Kappeler R, Kutlar Joss M Künzli N, Hoffmann B. Health effects of ultrafine particles: a systematic literature review update of epidemiological evidence. Int J Public Health. 2019:64(4):547-559.

96. Conti S, Lafranconi A, Zanobetti A, Cesana G, Madotto F, Fornari C. The short-term effect of particulate matter on cardiorespiratory drug prescription, as a proxy of mild adverse events. Environ Res. 2017;157:145152.

97. Pope CA 3rd, Ezzati M, Dockery DW. Fineparticulate air pollution and life expectancy in the United States. N Engl J Med. 2009;360(4):376-386.

98. Berhane K, Chang CC, McConnell R, et al. Association of changes in air quality with bronchitic symptoms in children in California, 1993-2012. JAMA. 2016;315(14): 1491-1501.

99. Pinault L, Tjepkema M, Crouse DL, et al Risk estimates of mortality attributed to low concentrations of ambient fine particulate matter in the Canadian community health survey cohort. Environ Health. 2016;15:18.

100. Di Q, Wang Y, Zanobetti A, et al. Air pollution and mortality in the medicare population. N Engl J Med. 2017;376(26):2513-2522

101. Franchini M, Mannucci PM. Mitigation of air pollution by greenness: A narrative review. Eur I Intern Med. 2018:55:1-5.

102. Chen C, Park T, Wang X, Piao S, et al. China and India lead in greening of the world through land-use management. Nat Sustain. 2019;2:122-129. 